\title{
Assessment of functional performance and sleep of children with congenital zika syndrome
}

\begin{abstract}
Purpose: Since the discernment of the infant functional repercussions is fundamental for the adequate therapeutic planning, the present study aimed to assess the functional performance and the sleep in children with Congenital Zika Syndrome (CZS).

Method: This is a cross-sectional, descriptive study. We selected children between 6 and 18 months of age diagnosed with CZS. For better assessing the results, the children were divided in two groups, of 6-11 months and of 12-18 months. A functional performance evaluation was performed using the Pediatric Evaluation of Disability Inventory (PEDI) and sleep assessment through the Brief Infant Sleep Questionnaire (BISQ), in addition to a questionnaire to characterize the sample.
\end{abstract}

Results: 79 children were included in this study. In the evaluation of the functional performance it was observed that $100 \%$ of the sample, presented delay in the area of mobility. In the evaluation of self-care and social function, there was a greater prevalence of delay in the age group of 12-18 months, when compared to the age group of 6-11 months. When comparing the group 6-11 months with the group 12-18 months, there was a significant difference for the gross scores among suitable children in the self-care domains $(\mathrm{p}=0.042)$ and social function $(\mathrm{p}<0.001)$ and for delayed children in the self-care and function domains $(\mathrm{p}<0.001)$. There was no significant difference for the mobility domain between the age groups $(\mathrm{p}=0.836)$.

Conclusion: Children had little capacity to perform functional skills in the areas of personal care, mobility, communication and social interaction, and sleeping habits within a typical pattern of child development.

Keywords: congenital zika syndrome, evaluation, child development, functional skills, sleep
Volume 5 Issue 6 - 2020

\author{
Danielly Laís Pereira Lima,' Carine Carolina \\ Wiesiolek, ${ }^{1,2}$ Maria Lucia Galvão Carvalho \\ Dias Correia,' Milena Guimarães Monteiro,' \\ Karla Mônica Ferraz',2 \\ 'Laboratory of Pediatrics Studies, Federal University of \\ Pernambuco, Brazil \\ 2Professor, Physical Therapy Department, Federal University of \\ Pernambuco, Brazil
}

\begin{abstract}
Correspondence: Danielly Laís Pereira Lima, LEPed Laboratório de Estudos em Pediatria, Departamento de Fisioterapia, Universidade Federal de Pernambuco. Rua Padre Carapuceiro, 468/504, Boa Viagem, Recife, Pernambuco, Brazil. CEP: $51020-280$, Tel 5581998739946 Email danilais.lima@gmail.com
\end{abstract}

Received: November 18, 2020 | Published: December 07, 2020
Abbreviations: $\mathrm{MH}$, ministry of health; CZS, congenital zika syndrome; $\mathrm{CP}$, cerebral palsy; NGO, non-governmental organizations; $\mathrm{STORCH}$, syphilis, toxoplasmosis, rubella, cytomegalovirus, herpes simplex; PEDI, pediatric evaluation of disability inventory; BISQ, brief infant sleep questionnaire; SPSS, statistical package for the social sciences

\section{Introduction}

During 2015, in Pernambuco, a state of Brazil's northeast, occurred an expressive increase of suspect cases of microcephaly in newborns, and this location remained for a long time as the one with the highest number of cases in the country. ${ }^{1}$ Since November from this same year, the European Centre for Disease Prevention and Control presented a possible association between Zika virus infection and the congenital microcephaly cases in Brazil. ${ }^{2}$ In December 2015, the Ministry of Health $(\mathrm{MH})$ related this association to the infection by Zika virus during the gestational period. Data from the last incidence report of 2016 showed that the cases reached 10.867 notifications with 2.366 of them investigated and confirmed. ${ }^{3}$

Some studies started to describe other characteristics among the affected children in addition to microcephaly, for example, neurologic findings (e.g. loss of brain volume, ventriculomegaly, subcortical calcifications, hypoplasia or absence of corpus callosum and decreased myelination) ${ }^{4,5}$ and ocular anomalies..$^{6,7}$ Moreover, the studies observed that those affections could be present without a concomitant microcephaly diagnostic. ${ }^{8}$ Taken together, these findings, associated or not with microcephaly, were grouped and originated the term Congenital Zika Syndrome (CZS). ${ }^{4,5}$

The neurological alterations reported on these infants were of a large extent and may be accompanied by spasticity or hypertonia, hyper reflexia and excessive irritability, ${ }^{9-12}$ possibly generating significant motor disabilities, which are similar to a mixed cerebral palsy (CP). ${ }^{8}$ It is necessary to highlight that the previous studies ${ }^{4,5,7,11}$ described the children evaluation at the point of view of neuroimaging and visual assessment, with few of them analyzing the functional abilities and/or motor development. Furthermore, the studies that indeed used a more functional approach did not have a large number of sample ${ }^{9}$ or just made a description about the clinical findings ${ }^{11}$ without any specific functional assessment.

Therefore, on the behalf of understanding this new clinical condition, the present study aimed to assess the functional performance and sleep in children with CZS, since the discernment of the infant functional repercussions is fundamental for the adequate long-term therapeutic planning and follow-up.

\section{Methods}

The study design is observational. Rehabilitation services, hospitals, non-governmental organizations (NGO) and the Regional Health Management of the Government of the State of Pernambuco were contacted for the research accomplishment. After their consent, the infants were recruited at Hospital das Clínicas of the Federal University of Pernambuco, non governmental organization (NGO) 
Alliance of Mothers and Rare Families and in domiciliary visits made by the supporters of microcephaly of the II and XII Regional Health Management, which includes 31 cities of the state of Pernambuco. Data gathering was conducted during September 2016 to March 2017.

\section{Population}

This study included infants aging 6 to 18 age of life, diagnosed with CZS or Congenital Infection by STORCH (syphilis, toxoplasmosis, rubella, cytomegalovirus, herpes simplex) + Zika. The cases should comply the following classification used by the $\mathrm{MH}$ : confirmed case of congenital infection by Zika or possible case of congenital infection by STORCH + Zika, described respectively as neurological, visual or hearing manifestations, with positive laboratorial results or reagent for Zika virus and mother reporting exanthema or fever with no definite cause during pregnancy; or newborn with neurological, visual or hearing manifestations with inconclusive laboratorial results for STORCH + Zika on the mother and newborn samples. ${ }^{13}$ Infants with microcephaly attributable to non-congenital causes or any other causes except the cited above were excluded. ${ }^{7}$

The research was approved by the Ethical Committee of Federal University of Pernambuco (CAAE- 47494115.3.0000.5208) and the population was based upon the 378 cases of congenital syndromes confirmed and investigated at the state of Pernambuco. ${ }^{14}$ The sample size calculation was performed with a sample of 31 infants. The use of Openepi website showed the following frequencies (infants classified with delay): $35 \%$ with delay on self-care area, $99 \%$ with delay on mobility area and 19\% with delay on social function area. We estimated the absolute error of $10 \%$ and confidence level of $95 \%$, using the largest sample within the three areas, resulting in a number of 72 infants, with an additional of $10 \%$ to prevent possible losses, totalizing 79 infants.

\section{Functional performance assessment}

The instrument used to assess the functional performance was PEDI - Pediatric Evaluation of Disability Inventory, on its Portuguese version, validated in 2005 for the Brazilian population. ${ }^{15}$ The interview method was applied for the instrument implementation, where the caregivers (mother, father or responsible) answered the questions stablished by the questionnaire on a reserved place. ${ }^{15,16}$

This study used the part I of the instrument, regarding to functional abilities, which consists of child assessment on three areas: Selfcare Area - feeding abilities, personal care, dressing up and toilet usage; Mobility Area - transfers and mobility on indoor and outdoor environments; Social Function Area - communication capacity, social interaction, community and domestic tasks. ${ }^{15,16}$

Once the items punctuation of each area is completed, a brute score informs the total amount of points scored on the evaluated areas. The transformation of the brute score into a normative score allows the classification regarding to functional performance. Normative scores ranging 30 to 70 are indicatives of adequate functional performance for Brazilian children with a typical development. Values under 30 are classified as delayed functional performance or significantly lower performance in relation to children of the same age group. ${ }^{15}$

\section{Sleep assessment}

The Brief Infant Sleep Questionnaire (BISQ) is a single multidimensional measure, which is suitable to apply with infants. It consists of a screening tool performed by the parents or caregivers, who assess the sleep alterations of infants aging 0-29 months of life.
The questionnaire contains 13 items and was translated to Portuguese maintaining the same quantity of items from the original scale and its durations ranges from five to 10 minutes..$^{17,18}$

The caregiver conducts the assessment, approaching the following items: Nocturnal sleep duration; daytime sleep duration; number of night wakings; duration of wakefulness during the night; nocturnal sleep-onset time; settling time (latency to falling asleep for the night); method of falling asleep; location of sleep; preferred body position; age of child; gender of child; birth order; and role of responder. ${ }^{17,18}$

The data analysis was calculated by the software Statistical Package for the Social Sciences (SPSS) for Windows (Version 16.0). Regarding to the descriptive analysis, the infants were classified in two groups according to the age group: one group with infants aging 6 to 11 months and the other group with infants aging 12 to 18 months. This division followed the same age group described on the PEDI manual. ${ }^{15}$ The socio demographic and anthropometric variables were described by frequency distribution for the categorical variables and by mean and standard deviation (SD) for the continuous variables. The normal distribution of the continuous variables was assessed by the Kolmogorov-Smirnov test and the hypotheses of equality of variances by the $\mathrm{F}$ de Levene test. The significance considered was a value of $\mathrm{p}<0,05$.

\section{Results}

88 mothers were invited to participate on this study, of which 9 were excluded because three of them had infants presenting positive serology exclusively to STORCH, two of them had infants older than 18 months of life, two of them had infants with microcephaly diagnostic after a possible case of gestational Chikungunya and two of them because they did not show positive serology for Zika virus, neither any report of cutaneous rash during pregnancy and additionally did not show any neuroimaging without suggestive signs of congenital infection. In total, 79 infants with CZS were included in the study; all of them were born in the state of Pernambuco, of which 43 from Metropolitan Recife and 36 from countryside.

Table 1 presents the sample characterization, including maternal and infant data, the last divided by age group, as follows: the first group composed infants aging 6 to 11 months $(n=31)$ and the second group composed of infants aging 12 to 18 months $(n=48)$.

The functional performance assessment showed, by the classification of normative scores, that $100 \%$ of the sample presented delay on the mobility area in both groups. Regarding to the first group, the following was observed: $22(71 \%)$ infants classified as adequate on the self-care area, $27(87 \%)$ infants classified as adequate on the social function, $9(29 \%)$ infants delayed on self-care area and $4(13 \%)$ delayed on the social function area. The second group showed: 3 $(6,2 \%)$ infants classified as adequate on the self-care area, $(16,7 \%)$ classified as adequate on the social function, $(93,8 \%)$ infants delayed on self-care area e $40(83,3 \%)$ delayed on the social function area.

In order to better understanding the data, the Table 2 illustrates the results of each group, with the brute scores acquired on the assessment of the functional performance regarding to the areas of self-care, mobility and social function.

Moreover, from the brute scores (total number of points for each area) the means and standard deviations were calculated following the age stratification and the PEDI classification of normal or delayed. Table 2 presents the comparison between group ages of the normal and delayed infants. 
Table 3 presents detailed data about the sleep description of the assessed infants, presenting the number of infants and frequency for each item of the 10 evaluated questions.

\section{Discussion}

This study reported the functional performance and sleep characteristics of 79 infants with CZS. Our findings corroborate with previous studies that showed more than $60 \%$ of the mothers presenting arbovirosis symptoms during pregnancy also had cutaneous rash during first trimester and more than $80 \%$ of the babies were born with at least 37 weeks., ${ }^{411,12}$ In our sample, $39 \%$ of the mothers reported having knowledge of the microcephaly condition already during pregnancy. The mean number of pre-natal consultations reported by the mothers was eight, showing to be higher than the number of consultations preconized by $\mathrm{MH}$ in Brazil. ${ }^{19}$

The PEDI assessment demonstrated a higher prevalence of infants of the age group 12-18 months classified as delayed for the self-care and social functional areas. When performing the evaluation of the brute score means, we observed a small variation on the mean values between the age groups 6 to 11 months and 12 to 18 months. With respect to age comparison, we observed that self-care and social function areas revealed significant differences between age groups, thus demonstrating that older infants had different acquisitions in comparison to the infants with lower age.

Nevertheless, the evolution of the functional abilities is still limited. When we evaluated the progress of daily activities, for example, chew and swallow; we verified that most of the younger infants scored on crushed or wrinkled food only, while the other age group scored on wrinkled food and in some cases, ground food. A very small number of infants, however, scored on chopped food, once the punctuation on this item needs from the infant the ability to chew or crunch. ${ }^{15}$ These findings suggest that older infants, even though presenting a higher score, showed a functional performance similar to the younger infants. These results correspond with the literature reports about the presence of dysphagia on CZS children. ${ }^{5,8}$

The entire sample presented a delay for the mobility area. The mothers did not report simple activities such as intentional indoor locomotion, pulling or pushing any object, or any activity requiring a minimal level of transfer. When comparing the ages, we observed that only the mobility area did not present statistical difference between age groups, hence indicating that infants aging 12-18 months scored the same mobility items of the 6-11 months infants, a behavior suggesting motor stage stagnation and lack of performance on active moving.

Until the present moment, there is a lack of the literature about the assessment of the functional performance of infants with CZS. Alternatively, evidence about mobility and transfer of children with cerebral palsy can contribute for the understanding of the possible repercussions for the CZS children, once both of them probably will share a similar motor behavior. ${ }^{8}$

Literature indicates that children with cerebral palsy and reduced mobility are more prone to have pain, sleep disturbances, and require more frequently enteral nutritional support. ${ }^{20-23}$ It is also known that the decrease of active moving on CP children favors lower levels of physical activity, higher risk of low bone mineral density and alterations on bone growth because of negative neurotrophic factors..$^{22,24-26}$

The delay indexes in functional performance found in our study may be associated with the neurological damage presented in children infected by Zika. These damages include a massive alteration of the structure and development of the brain after birth and may reflect on changes in tonus and involuntary contractions, ${ }^{4,5,9,12}$ possibly the explanation of the negative repercussions on the motor performance highlighted by our study.

In relation to sleep results, $75,9 \%$ of the mothers did not consider the sleep of their infants a problem. This may be justified because these infants typically present a long sleep duration, with $88,5 \%$ of them waking just once or not waking at all during the night sleep and $67 \%$ of them sleeping between 8 to 12 hours per night. These results reveal that most of the evaluated infants presented adequate sleep habits, which can be exemplified by that fact that part of the sample had at least 13 hours of sleep per day, considered adequate by the literature and $\mathrm{MH}^{27,28}$

Literature did not show any information reporting the sleep of CZS children. However, some studies presented cases of epileptic crises and excessive irritability in this population, ${ }^{4,10,12,29}$ dysfunctions that could interfere the sleep quality. On the other hand, the irritability seemed to be more related to younger infants, decreasing its level after 6 months of age, thus an impairment incapable of negatively intervene on the sleep habits when we confront this information to our sample. Studies approaching CP children with similar levels of immobility report sleep disturbances, ${ }^{29,30}$ however our results presented different conclusions, which can be justified by the fact that our sample aged less than 18 months of age while the CP studies had higher age sample.

Our study had some limitations. The use of BISQ was one of them, because it is a screening tool, but the choice can be explained by its application facilities. Another point to be considered is the non-collection of information about the used medicines, which could intervene on the sleep assessment.

Lastly, when we report the functional performance indexes and sleep assessment it is possible to provide quantitative data to improve the specialized therapeutic management, with possible data for the formulation of public policies on health area providing enhancements of the integral care.

Our results raise awareness in relation to the need of mobility devices, once our sample showed impacting data on mobility area, reflecting an important limitation on active moving and impairment on functional performance due to CZS.

\section{Conclusion}

Our study reports the functional performance and sleep habits of infants with CZS aging 6 to 18 months of age, who presented in majority a decreased performance of functional abilities on the areas of self-care, mobility, communication, social interaction, but a typical pattern of sleep habits normally seen in children under development. At first, these results may indicate the chronicity of this syndrome and reflect how much these children will become dependents, with the need of multi-professional care and a supportive network that should be extended to the family. This study is the first stage of a bigger research project that accompanies the development of children with SCZ aiming to provide quantitative data for a better understanding of children with SCZ and consequent therapeutic planning.

\section{Acknowledgements}

None.

\section{Conflicts of interest}

No potential conflict of interest relevant to this article was reported. 


\section{References}

1. Brasil. Protocolo de vigilância e resposta à microcefalia relacionada à infecção pelo vírus zika. Ministério da Saúde, Versão 12 - 09/12/2015. 2015 .

2. European centre for disease prevention and control. rapid risk assessment: microcephaly in Brazil potentially linked to the Zika virus epidemic - 24 November 2015. Stockholm: ECDC; 2015.

3. Brasil. Informe epidemiológico $n^{\circ} 57$ - Semana Epidemiológica (SE) 52/2016 (25 a 31/12/2016) Monitoramento dos casos de microcefalia no Brasil.

4. Aragão M de FV, van der Linden V, Brainer-Lima AM, et al. Clinical features and neuroimaging (CT and $\mathrm{MRI}$ ) findings in presumed Zika virus related congenital infection and microcephaly: retrospective case series study. Bmj [Internet]. 2016;353:i1901.

5. Moore CA, Staples JE, Dobyns WB, et al. Characterizing the pattern of anomalies in congenital zika syndrome for pediatric clinicians. JAMA Pediatr [Internet]. 2016;1-8.

6. van der Linden V, Filho ELR, Lins OG, et al. Congenital zika syndrome with arthrogryposis: retrospective case series study. BMJ [Internet]. 2016;354(5):i3899.

7. Ventura CV, Ventura LO, Bravo-Filho V, et al. Optical coherence tomography of retinal lesions in infants with congenital zika syndrome. JAMA Ophthalmol [Internet]. 2016;62(12):1-8.

8. van der Linden V, Pessoa A, Dobyns W, et al. Description of 13 Infants born during October 2015-January 2016 with congenital zika virus infection without microcephaly at birth — Brazil. MMWR Morb Mortal Wkly Rep [Internet]. 2016;65(47):1343-1348.

9. Botelho A, Neri L, Silva M, et al. Infecção congênita presumível por Zika vírus : achados do desenvolvimento neuropsicomotor - relato de casos. Rev Bras Saúde Matern Infant. 2016;16.

10. Miranda-Filho D, Martelli CMT, De Alencar Ximenes RA, et al. Initial description of the presumed congenital Zika syndrome. Am J Public Health. 2016;106(4):598-600.

11. Moura da Silva AA, Ganz JSS, Sousa P da S, et al. MJR. Early growth and neurologic outcomes of infants with probable congenital zika virus syndrome. Emerg Infect Dis [Internet]. 2016;22(11):1953-1966.

12. Schuler-Faccini L, Ribeiro EM, Feitosa IM, et al. Possível associação entre a infecção pelo vírus zika e a microcefalia - Brasil, 2015. Weekly. 2016;65(3).

13. Brasil. Orientações integradas de vigilância e atenção à saúde no âmbito da Emergência de Saúde Pública de Importância Nacional. Ministerio da Saúde. 2016.

14. Brasil. Informe epidemiológico $\mathrm{n}^{\circ} 41$ - Semana Epidemiológica (SE) 34/2016 (21/08/2016 A 27/08/2016) monitoramento dos casos de microcefalia no Brasil. Ministério da Saúde. 2016;1-4.
15. Mancini MC. Inventário de avaliação pediátrica de incapacidade (P.E.D.I.), Manual da versão brasileira adaptada. Minas gerais: Editora UFMG; 2005.

16. Haley S, Coster W, Ludlow L, et al. Pediatric evaluation of disability inventory: development, standardization and administration manual. Bost New Englang Med Cent. 1992.

17. Nunes ML, Kampff J de la PR, Sadeh A. BISQ questionnaire for infant sleep assessment: translation into brazilian portuguese. 2012;5(3):89 91.

18. Sadeh A. A brief screening questionnaire for infant sleep problems: validation and findings for an Internet sample. Pediatrics [Internet] 2004;113(6): $570-577$.

19. Brasil. Pré-Natal E Puerpério. Ministério da Saúde, Normas e manuais técnicos. 2006;1:162.

20. Alriksson-Schmidt A, Hägglund G. Pain in children and adolescents with cerebral palsy: a population-based registry study. Acta Paediatr [Internet]. 2016;105(6):665-670.

21. Guideline Alliance (UK). Cerebral palsy in under 25s: assessment and management. London: national institute for health and care excellence (UK); 2017

22. Rempel G. The importance of good nutrition in children with cerebral palsy. Phys Med Rehabil Clin N Am [Internet]. 2015;26(1):39-56.

23. Romeo DM, Brogna C, Quintiliani M, et al. Sleep disorders in children with cerebral palsy: neurodevelopmental and behavioral correlates. Sleep Med [Internet]. 2014;15(2):213-218.

24. Hough JP, Boyd RN, Keating JL. Systematic review of interventions for low bone mineral density in children with cerebral palsy. Pediatrics. 2010;125(3):e670-678.

25. Keawutan P, Bell K, Davies PSW, et al. Systematic review of the relationship between habitual physical activity and motor capacity in children with cerebral palsy. Res Dev Disabil [Internet]. 2014;35(6):1301-1309.

26. Oeffinger D, Conaway M, Stevenson R, et al. Tibial length growth curves for ambulatory children and adolescents with cerebral palsy. Dev Med Child Neurol. 2010;52(9):195-201.

27. Brasil. Cadernos de atenção básica - saúde da criança: crescimento e desenvolvimen to. Ministério da Saúde. 2012.

28. Ednick M, Cohen AP, McPhail GL, et al. A review of the effects of sleep during the first year of life on cognitive, psychomotor, and temperament development. Sleep [Internet]. 2009;32(11):1449-1458.

29. Alves LV, Di D, Sousa C. Crises epilépticas em crianças com síndrome congênita do Zika vírus. Rev Bras Saúde Matern Infant. 2016;16:33-37.

30. Dutt R, Roduta-Roberts M, Brown C. Sleep and children with cerebral palsy: a review of current evidence and environmental nonpharmacological interventions. Children [Internet]. 2015;2(1):78-88. 